PRIFYSGOL

glyndŵn

Glyndŵr University

Glyndŵr University Research Online

Advanced Materials Research Laboratory

Materials Science

$8-1-2004$

\title{
Biomedical Applications of Batteries
}

Roger Linford

Glyndwr University, r.linford@glyndwr.ac.uk

R Latham

De Montfort University

W Schlindwein

De Montfort University

Follow this and additional works at: http://epubs.glyndwr.ac.uk/amrl

Part of the Analytical, Diagnostic and Therapeutic Techniques and Equipment Commons, and the Biomedical devices and instrumentation Commons

\section{Recommended Citation}

Linford, R., Latham, R. \& Schlindwein, W. (2004) 'Biomedical Applications of Batteries'. Solid State Ionics, 177(19-25), 1559-1565

This Article is brought to you for free and open access by the Materials Science at Glyndŵr University Research Online. It has been accepted for inclusion in Advanced Materials Research Laboratory by an authorized administrator of Glyndŵr University Research Online. For more information, please contact d.jepson@glyndwr.ac.uk. 


\title{
Biomedical Applications of Batteries
}

\begin{abstract}
An overview is presented of the many ways in which batteries and battery materials are used in medicine and in biomedical studies. These include the use of batteries as power sources for motorised wheelchairs, surgical tools, cardiac pacemakers and defibrillators, dynamic prostheses, sensors and monitors for physiological parameters, neurostimulators, devices for pain relief, and iontophoretic, electroporative and related devices for drug administration. The various types of battery and fuel cell used for this wide range of applications will be considered, together with the potential harmful side effects, including accidental ingestion of batteries and the explosive nature of some of the early cardiac pacemaker battery systems.
\end{abstract}

\section{Keywords}

Batteries, Biological physics instrumentation, Implants, Fuel cells, Medical applications, pacemakers

\section{Disciplines}

Analytical, Diagnostic and Therapeutic Techniques and Equipment | Biomedical devices and instrumentation

\section{Comments}

Copyright (C) 2004 Elsevier B.V. All rights reserved. Proceedings of the Fifteenth International Symposium on the Reactivity of Solids published in Solid State Ionics in 2006. The origional published version of this article is available at sciencedirect.com 


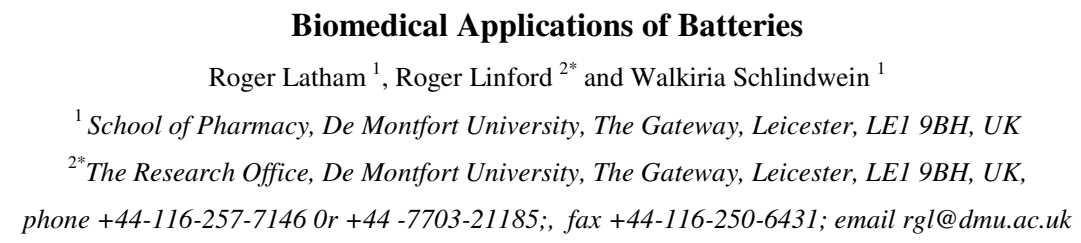

\begin{abstract}
An overview is presented of the many ways in which batteries and battery materials are used in medicine and in biomedical studies. These include the use of batteries as power sources for motorised wheelchairs; surgical tools; cardiac pacemakers and defibrillators; dynamic prostheses; sensors and monitors for physiological parameters; neurostimulators; devices for pain relief; and iontophoretic, electroporative and related devices for drug administration. The various types of battery and fuel cell used for this wide range of applications will be considered, together with the potential harmful side effects, including accidental ingestion of batteries and the explosive nature of some of the early cardiac pacemaker battery systems.
\end{abstract}

PACS codes and keywords: Batteries; Biological Physics Instrumentation; Implants; Fuel Cells; Medical Applications; 84.60D; 87.80 


\section{Introduction}

The importance of electrochemistry in facilitating and controlling the passage of ions in living tissues is universally acknowledged. Without redox reactions taking place within the body, life as we know it would cease. Electrochemistry is also responsible for the production and storage, in power sources such as batteries and fuel cells, of electrical energy from chemical reactions.

Here we will review two main ways in which battery science and technology is utilised to enhance the quality of life in humans. The first is where devices and power sources are external to the part of the body where the particular equipment functions, as is the case with a transdermal iontophoretic device [1]. The second is where the device can be implanted at the site of action and the battery is either external or implanted in a different but convenient location. An example is a heart pacemaker battery which powers an electrode attached to the heart. The battery is implanted outside the thoracic cavity.

The timeliness of the topic of biomedical electrochemical applications is well illustrated by the decision of the Electrochemical Society to feature four articles on electrochemistry in medical applications, in the most recent, fall 2003, issue of Interface [2-5]. These cover such topics as electro-chemically modified shape-memory Nitinol alloys for stents used to open blocked arteries [3] and drug reservoirs made from electrochemically deposited, thin metallic films [6].

\section{Medical applications using external devices}

\subsection{Transdermal, including iontophoretic, devices}

Electric shocks from torpedo fish were used in ancient Greece to treat gout and the first example of the use of an electric current to increase penetration of ionic drugs into and through surface tissue was in 1747 [7]. The term iontophoresis was introduced for this process in the $19^{\text {th }}$ century [8].

Drugs can be encouraged to penetrate the skin by

- Chemical penetration enhancers such as surfactants [9]

- Phonophoresis or Sonophoresis in which ultrasound is used [10]

- Iontophoresis, which works only on ionic drugs. It can be used for controlled delivery and for non-invasive monitoring, as counter ions leave the skin to compensate for the charge of inserted drug ions $[1,7,11,12]$ 
- Electroporation in which $90 \mathrm{~V}$ pulses open the skin pores to let large neutral or charged molecules pass [13-15]. It is useful for delivering gene-based biodrugs

- Electro-osmotic flow in which a voltage gradient across a porous medium such as the skin causes a bulk volume flow in the same direction as the passage of counter ions in iontophoresis. It can be used to deliver neutral or cationic drugs, skin being negatively charged, but it is not useful for peptide or nucleotide drugs, which are anionic. Diffusion is not involved [1, $9,16]$

- Reverse iontophoresis in which body fluids can be sampled by electro-osmotic flow sampling from the body [17-19]

There are many subtle variants and combinations of electrically assisted transdermal methods such as a.c. [20] and switching [21] iontophoresis and jet injection combined with iontophoresis [22]. A variety of drugs can be iontophoretically delivered, including lidocaine for local anaesthesia [23] and acetic acid for tendonitis of the shoulder [24]. The drug reservoir can be formed from many materials including polymer electrolytes [1. 7]. Many parts of the body can be addressed, including teeth [17] and eyes [25, 26]. Vasodilatation is less pronounced for anodal than for cathodal drugs [27] and zwitterionic drugs such as aminolevulinic acid (ALA) are more efficiently delivered from the anode than the cathode [28].

\subsection{Left Ventricular Assist Devices (LVADs) and Total artificial hearts}

LVADs are pumping mechanisms directly attached to the heart that can be used for patients awaiting heart transplants or to treat severely damaged hearts. The power requirements are too great to be satisfied entirely by implanted secondary batteries. The patient wears a vest-like battery pack and power is transmitted to the device through the skin. An internal battery, functioning for an hour each day, provides backup, and also less restriction [29, 30].

A total artificial heart is an implanted mechanical replacement for the entire damaged heart and, like the LVAD, is powered with a combination of external and internal batteries [4].

\subsection{Surgical Implements}

Portable medical devices and cordless surgical tools generally involve the use of conventional battery systems which are nowadays sufficiently well encapsulated to meet the stringent requirements of the clinical environment. These may use either primary or secondary batteries and in, in hand-held tools and devices, the emphasis is on the battery-power management technology with compact configurations and rechargeable convenience, such as the development of rechargeable battery handles for medical diagnostic instruments [31,32] 


\subsection{Dynamic Prostheses}

Prototype devices are being developed to take over the functions of the semicircular canals in the ear, which act as physiological rotation sensors to preserve balance. They use piezoelectric vibrating gyroscopes to measure the angular velocity of the head. Pt electrodes are powered by Li batteries which, together with the sensors and computerised frequency converters are mounted externally [33]

\subsection{Motorised wheelchairs}

Wheelchairs are mostly powered by deep-discharge Lead-Acid batteries [34]. The range of power wheelchairs can be increased by the use of wet, rather than gel, batteries and can be over $50 \mathrm{~km} \mathrm{[35].}$

2.6 Sensors and monitors for physiological parameters

Multi-channel, general purpose, lightweight, low power consumption, portable monitors have been developed to monitor such physiological parameters as bladder pressure, body temperature and exposure to pollutants [36]. Battery powered glucose monitors are used by diabetics; halter monitors which continually store electrocardiogram signals for 24 hours help the cardiologist; and portable blood pressure readings can be used directly by patients to monitor their condition [4].

\section{Medical applications using implants}

There is a forty year history of successful, diverse, battery-powered devices with a range of current and energy demands ranging from $\mu \mathrm{A}$ for heart pace-makers, through $\mathrm{mA}$ for neurostimulators to the need to provide $40 \mathrm{~J}$ in a few seconds for implantable defibrillators [4].

\subsection{Cardiac pacemakers}

The first cardiac pacemaker was implanted in $1960[4,37]$ and was used to treat bradycardia. This is an illness where the heart beats too slowly and it can be caused by a variety of conditions including parasites (Chagas disease) and sick sinus syndrome. The first Li-powered pacemaker was implanted in 1972 [38] and Li// $\mathbf{L}_{2}-\mathrm{PVP}$ (Poly 2-vinyl pyridine) primary 
batteries are now almost universally used in the half a million pacemakers now implanted annually[4]. Biventricular pacing in both the right and left ventricles can treat congestive heart failure, a major cause of death. [39].

The power source is connected to electrodes in the heart and the leads are now electroplated and then protected by an organic layer to prevent scarring of the contacting tissue which increases resistance [40]. The possible effects of exposure to e.m. fields close to $50 / 60 \mathrm{~Hz}$ power line fields on pacemaker leads inserted in either the atrial or ventricular electrodes in the heart have been calculated [41].

3.2 Implantable Cardiac Defibrillators (ICD)

Tachycardia, a medical condition where the heart beats too fast, degenerates into ventricular fibrillation and death if untreated. The first ICD, which sensed and stopped fibrillation, was developed in 1980 and used a $\mathrm{Li} / \mathrm{V}_{2} \mathrm{O}_{5}$ battery to power an electrode sutured onto the heart [42]. Nowadays, ICDs treat tachycardia before fibrillation develops, whilst also acting as pacemakers. Additionally, they can provide a 40J shock via a transvenous lead if fibrillation occurs [4]. ICDs now have volumes of less than $35 \mathrm{~cm}^{-3}$.

There was concern, in the early days of mobile phone technology, that cellphones could interfere with the ICD pulse generator but no accidental triggering was found to occur so long as the phone was over $6 \mathrm{~cm}$ from the device [43].

\subsection{Neurostimulators and pain relief}

These are pacemaker-like devices that can be used for many purposes including blocking pain [4, 44]. Functional Neuromuscular Stimulators (FNS) have been developed to help paraplegic patients walk short distances ranging from at least 30 feet to 1 mile. Finger-touch buttons on a walking frame control a microcomputer that distributes stimulation signals across the skin to trigger action potentials in selected peripheral nerves. The device is at present powered by 8 AA batteries [45] but the power demand is potentially in the range of an implanted battery.

Based on the finding that low-frequency $(50 \mathrm{~Hz})$ electrical stimulation of the ventral intermediate thalamic nucleus decreased tremor in Parkinson's disease [46], battery-powered stimulators controlling implanted electrodes have been used successfully in drug-resistant patients [47] and over 14,000 patients have been treated since 1997 [44]. It used to be thought that deep brain stimulation (DBS) systems should be disconnected before cardiac defibrillators were implanted but a recent study has shown that DBS systems can be retained [48]. Optimisation studies to maximise battery life have been reported [49]. Incontinence has also been treated by stimulation of the sacral nerve [44] and epilepsy by vagal nerve stimulation [50]. 
Pain relief can also be provided by transcutaneous electrical nerve stimulation (TENS) using external batteries [4].

3.4 Implanted drug delivery devices

Drug therapy is most effective if the drug is delivered to the right place and at the right rate so that lower doses can be used. Delivery targeted to location and programmed in dosage can be achieved by implantable drug delivery systems consisting of electronic controls, a drug reservoir that can be refilled transcutaneously, a catheter to deliver the drug to the internal site and a mechanical bellows pump or a battery [51]. Applications include chronic pain treatment, chemotherapy and side-effect-free insulin delivery for diabetic patients [52].

3.5 Implanted hearing aids

Many devices, ranging from converters of acoustic signals to mechanical energy which are suitable for patients with some residual hearing [53] to cochlear implants for the profoundly deaf [54] are now commonly implanted. They are usually powered by secondary, often Li-ion, batteries. Other devices, powered by primary $\mathrm{Li} / \mathrm{I}_{2}-\mathrm{PVP}$ batteries and physically resembling pacemakers, replace a part of the ossicular chain with a piezoelectric sensor [55].

\section{Types of battery for biomedical applications}

\subsection{Lead-acid batteries}

Capacity loss after prolonged storage, caused by accumulation of lead sulphate, is a problem in sealed lead-acid (SLA) batteries used for external cardiac defibrillators. Appropriate maintenance protocols have been designed to assist emergency medical services to keep batteries in a constant state of readiness [56].

\subsection{Lithium batteries}

The use of Li batteries in implantable biomedical devices over the last 30 years has been recently reviewed [57, 58]. For low rate applications such as pacemakers the standard primary cell is $\mathrm{Li} / \mathrm{I}_{2}-\mathrm{PVP}[4,59]$. Originally it was thought that the system was formed solely from the two electrode layers, the assumed electrolyte being LiI created in situ [60]. It was later 
suggested that a liquid decomposition product of PVP was the actual electrolyte [61] but it is now thought that the original LiI concept is correct as the resistance increases with usage because of the growth in the electrolyte layer thickness [4].

Pacemakers with telemetry features require higher current delivery and hybrid cathodes are used [57].

Neurostimulators deliver mA pulses, as opposed to the much lower current, $5-20 \mu \mathrm{A}$ pulses of a pace-maker and, as is the case for implantable drug delivery systems, $\mathrm{Li} / \mathrm{CF}_{\mathrm{x}}$ or $\mathrm{Li} / \mathrm{SOCl}_{2}$ batteries are commonly used.

For high rate defibrillators/ cardioverters, $\mathrm{Li} / \mathrm{V}_{2} \mathrm{O}_{5}$ was originally used [62] but now either Li/ $\mathrm{Ag}_{2} \mathrm{~V}_{4} \mathrm{O}_{11}(\mathrm{SVO})$ [63, 64], $\mathrm{Li} / \mathrm{CF}_{\mathrm{x}}[65]$ or $\mathrm{Li} / \mathrm{MnO}_{2}(\mathrm{MDX})$ is preferred. $\mathrm{Li} / \mathrm{SVO}$ batteries have a calculated maximum random failure rate of $0.005 \%$ per test month [66]. Hybrid high/low rate systems have been developed [67] which provide energy densities of $650 \mathrm{~mW} \mathrm{~h}$ $\mathrm{cm}^{-3}$. Li-ion secondary batteries are now being used for both artificial hearts and LVADs [29, 30]

For hearing aid devices (HAD), 10 mA.h, $3.75 \mathrm{~V}$ secondary Li-ion 312-button cells are used which safely produce 10s pulses of $100 \mathrm{~mA}$ over background currents of $10 \mu \mathrm{A}$ [68].

\subsection{Other batteries}

The first implantable pacemaker in 1960 was powered by the Ruben $\mathrm{Zn} / \mathrm{HgO}$ cell [37, 69]. Proton exchange membrane fuel cells can replace lead-acid batteries for total artificial hearts and LVADs [70] and give up to 14 h of operation for a $1360 \mathrm{~g}$ power source compared with only $5 \mathrm{~h}$. for conventional lead-acid batteries. Up to $230 \mathrm{Wh} \mathrm{kg}^{-1} \mathrm{can}^{\mathrm{be}} \mathrm{obtained}$ if a hydrogen source is attached to the cell to permit replenishment.

\subsection{Supercapacitors}

These electrochemical devices have capacitances typically 50 times greater than electrolytic capacitors [71]. Batteries are usually optimised for maximum energy density $\left(\mathrm{J} \mathrm{cm}^{-3}\right)$ or specific energy $\left(\mathrm{J} \mathrm{kg}^{-1}\right)$. Supercapacitors provide short pulses of relatively high power, as required by many of the implantable medical devices [72] although these often also need a background trickle current which supercapacitors cannot easily provide.

\section{Recharging mechanisms}

5.1 Electrical 
Capacity fade in Li-ion batteries depends on cell configuration. After 300 cycles of $\mathrm{C} / 2$ charge and $1 \mathrm{C}$ discharge,

cylindrical cells were found to be better than prismatic cells, having faded by $16 \%$ rather than 24\% [73]. Charging

defibrillator power supplies presents a different set of problems as power factor correction is important for such pulsed power

loads [74].

5.2 Mechanical

Battery exhaustion accounts for one-third of all pacemakers sold. The potential use of a wrist-watch automatic

generating system (AGS), actuated by walking and body movement, to recharge pacemaker batteries was investigated but the power output is only a fraction of that required [75]. An AGS has been placed directly on a beating heart; it generated $13 \mu \mathrm{J}$ per heartbeat. $420 \mathrm{~mJ}$ are needed to pace a heart at 140 beats per minute for 60 minutes and it is plausible that sufficient charge could be stored in a capacitor at $2 \mathrm{~V}$ to make a practical device [76].

\subsection{Wireless}

A solar cell combined with a wireless charging system has been used to increase the battery running time of the totally implantable artificial heart [77].

\section{Dangers and difficulties}

\subsection{Thermally induced explosions}

More pacemakers and defibrillators are being implanted now and a greater proportion of the dead are cremated rather than buried. Half the Crematoria in the UK experience pacemaker explosions which can cause structural damage and injury $[78]$

6.2 Early pacemaker battery technology

The Ruben heart pacemaker cell [69] evolves $\mathrm{H}_{2}$ which makes hermetic sealing impossible and leads to unpredictable end-of-life within 18 to 36 months [4]. Disquieting as this battery failure is for the patient, it is not as traumatic as the effect of an implanted early type of $\mathrm{Li} / \mathrm{SOCl}_{2}$ cell exploding. "D" cells of this type are "capable of imparting a definite translational 
motion to a brick wall" [79]. They were attractive because of an energy density of $1.2 \mathrm{~W} \mathrm{~h} \mathrm{~cm}^{-3}$ and $640 \mathrm{~W} \mathrm{~h} \mathrm{~kg}^{-1}$, resulting from the unusual situation that $\mathrm{SOCl}_{2}$ (and also $\mathrm{SO}_{2} \mathrm{Cl}_{2}$ ) acts as both a cathode and a non-aqueous electrolyte.

Thankfully, Li batteries soon came on the scene, the first successful implant being in Italy in 1972 [38] and a variety of cathodes including $\mathrm{CuS}, \mathrm{SOCl}_{2}$ and $\mathrm{AgCrO}_{4}$ were tried until $\mathrm{I}_{2}-\mathrm{PVP}$ was selected [4].

6.3 Ingestion

Button batteries in the oesophagus represent a medical emergency and need to be removed endoscopically but once in the stomach they will usually pass through the gastrointestinal tract without difficulty [80].

\section{Conclusions.}

Medical applications stretch the ingenuity of the battery designer to the uppermost. Characteristics such as total mechanical integrity and completely reliable lifetime characteristics, which are merely virtues in most battery systems, are absolutely vital for all medical applications and life-critical for implanted systems. Tremendous strides have been made in the last few years to provide the compact, lightweight batteries that have made possible many detection and treatment regimes that would have been beyond both technology and concept even a few years ago.

\section{References}

[1] R.J. Latham, R.G. Linford, W.S. Schlindwein, Ionics 9 (2003) 41

[2] M. Schlesinger., Interface 12 (2003) 19

[3] M.E. Gertner, M. Schlesinger, Interface 12 (2003) 20

[4] C.F. Holmes, Interface, 12 (2003) 26

[5] H.S. White, Interface, 12 (2003) 30

[6] M.E. Gertner, M. Schlesinger, Electrochem Solid-State Lett. 6 (2003) J4

[7] R.J. Latham, R.G. Linford, W.S. Schlindwein, in: Solid State Ionics, ed. B.V.R. Chowdari, S.R.S. Prabharan, M.

Yahaya, I.A. Talib (World Scientific, Singapore, 2002) p. 283

[8] A. Helmstadter, Pharmazie, 56 (2001) 583 
[9] A.K. Banga in: Electrically Assisted Transdermal and Topical Drug Delivery (Taylor and Francis, London, 1998)

[10] A. Tezel, A. Sens, S. Mitragotri, J Pharm. Sci. 92 (2003) 381

[11] M.B. Delgardo-Carro, R.H. Guy, STP Pharma Sci. 11 (2001) 403

[12] N. Kanikkannan, Biodrugs 16 (2002) 339

[13] Q.H. Hu, W.Q. Liang, Pharmazie 58 (2003) 192

[14] A.R. Denet, V. Preat, J. Controlled Release, 88 (2003) 253

[15] O.D. Uitto, H.S. White, Pharm. Res. 20 (2003) 646

[16] D. Marro, Y.N. Kalia, M.B. Delgado-Charro, R.H. Guy, Pharm. Res., 18 (2001) 1701

[17] K. Yokoyama, K Matsumoto, J. Murase, J. Clin. Laser Med and Surgery 18 (2000) 9

[18] N.Sekkat, A. Naik, Y.N. Kalia, P. Glikfeld, R.H. Guy, J. Controlled Release, 81 (2002) 83

[19] B. Ben-Zeev, N. Watemberg, A. Augarten, N. Barnd, Y. Yahav, O. Efrati, L. Topper, I. Blatt, J. Child Neurology 18 (2003) 254

[20] P.F. Meyer, L.I.E. Oddsson, J. Neurosci. Methods, 125 (2003) 209

[21] O. Ishikawa, Y. Kato, H. Onishi, T. Nagai, Y. Machida, Int. J. Pharmaceutics, 249 (2002) 81

[22] K. Sugibayashi, M. Kagino, S. Numajiri, N. Inoue, D. Kobayashi, M. Kimura, M. Yamaguchi, Y. Morimoto, J.

Pharm. Pharmacology, 52 (2000) 1179

[23] W.T. Zempsky, T.M. Parkinson, Dermatologic Surgery, 29 (2003) 627

[24] M. Perron, F. Malouin, Physical Therapy, 83 (2003) 71

[25] H. Sasaki, K. Yamamura, T. Mukai, K. Nishida, J. Nakamura, M. Nakashima, M. Ichikawa, Crit. Rev. Therapeutic Drug Carrier Systems, 16 (1999) 85

[26] M. Halhal, G. Renaard, R.A. Bejjani, F. Behar-Cohen, J. Francais Opthalmologie, 26 (2003) 391

[27] E.J. Droog, F. Sjoberg, Microvascular Res. 65 (2003) 172

[28] R.F. Lopez, M.V.L.B. Bentley, A.B. Delgado-Charro, R.H. Guy, J. Controlled Release 88 (2003) 65

[29] C.F. Holmes, R.A. Leising, D.M. Spillman, E. Takeuchi, ITE Battery Lett. 1 (1999) 132

[30] C.F. Holmes, J. Power Sources 97-8 (2001) 739

[31] R.G. Tiller, US Patent 4,991,069 (1991)

[32] J.D. Connors, US Patent 5,153,495 (1992)

[33] W.S. Gong and D.M. Merfeld, Ann. Biomedical Engng. 28 (2000) 572

[34] J.H. Aylor, A. Thieme, B.W. Johnson, IEEE Trans. Indust. Elect 39 (1992) 398 
[35] R.A. Cooper, D.P. Vansickle, S.J. Albright, K.J. Stewart, M. Flannery, R.N. Robertson, J. Rehab. Res. And Dev. 32 (1995) 255

[36] G.W. Petley, S. Clitheroe, F. Clewlow, C.D. Deakin, A.J. Chauhan, Med. Engng. Physics 20 (1998) 33

[37] W. Greatbatch, W. Chardack, Proc. New England Res. And Engng. Meeting 1 (1959) 8

[38] G. Antonioli, F. Baggioni, F. Consiglio, G. Grassi, R. LeBrun, F. Zanardi, Minerva Med. 64 (1973) 2298

[39] www.cooperhealth.org/news/resource/2002oct/05.htm

[40] M.H. Schoenfisch, M. Ovadia, J.E. Pemberton, J. Biomed. Mater. Res., 51 (1999) 209

[41] T.W. Dawson, K. Caputa, M.A. Stuchly, R.B. Shepard, R. Kavet, A. Sastre, IEEE Trans. Biomed. Engng., 49 (2002) 254

[42] M. Mirowski, M.M. Mower, P.R. Reid, Amer. Heart J., 1000 (1980) 1089

[43] H.I. Bassen, H.J. Moore, P.S. Ruggera, Pacing and Clin. Electrophysiology 21 (1998) 1709

[44] Neurological and Spinal Review www.medtronic.com/neuro (2003)

[45] D. Graupe, K.H. Kohn, Surgical Neurology, 50 (1998) 202

[46] A.L. Benabid, P. Pollak, A. Louveau, S. Henry, J. Derougemont, Appl. Neurophysiology 50 (1987) 344

[47] F. Alesch, M.M. Pinter, R.J. Helscher, L. Fertl, A.L. Benabid, W.T. Koos, Acta Neurochirgica 136 (1995) 75

[48] J.M. Rosenow, H. Tarkin, E. Zias, C. Sorbera, A. Mogilner, J. Neurosurgery, 99 (2003) 167

[49] P.E. O'Suilleabhain, W. Frawley, C. Giller, R.B. Dewey, Neurology, 60 (2003) 786

[50] R. Terry, W.B. Tarver, J. Zabara, Epilepsia 31 (1990) S33

[51] G. Spera, www.devicelink.com/archive/97/09/013.html (1997)

[52] C.D. Saudek, W.C. Duckworth, A. Globbie-Hurder, W.G. Henderson, J. Amer. Medical. Assn. 276 (1996) 1322

[53] G.R. Ball, J.M. Culp, C. Marr, R. Dietz, J. Salisbury, US Patent 5,624,376 (1997)

[54] L. Geier, L. Fisher, M. Barker, J. Opie, Annuals of Otology, Rhinology and Laryngology, 108 (1999) 80

[55] www.stcroixmedical.com/prod01.htm (2003)

[56] M.J. Cleland, J.P. Maloney, B.H. Rowe, J.Emergency Medicine 18 (2000) 305

[57] C.L. Schmidt, P.M. Skarstad, J. Power Sources 97-98 (2001) 742

[58] E.S. Takeuchi, R.A. Leising, MRS Bull. 27 (2002). 624

[59] J.R. Moser, US Patent 3,660,163 (1972)

[60] B.B. Owens, P.M. Skarstad, in: Fast Ion Transport in Solids, Electrodes and Electrolytes, ed. P. Vashishta, J.N.

Mundy, G.K. Shenoy (North-Holland, Amsterdam, 1979) p.61

[61] J.B. Phipps, T.G. Hayes, P.M. Skarstad, D.F. Untereker, Solid State Ionics, $18 \& 19$ (1986) 1073 
[62] R.J. Horning, S. Viswanathan, in: Proc. $29^{\text {th }}$ Power Sources Conf. (The Electrochemical Society, Pennington, NJ,

1980) p.64

[63] C.C. Liang, M.E. Bolster, R.M. Murphy, US Patent 4,310, 609 (1982)

[64] A.M. Crespi, S.K. Somdahl, C.L. Schmidt, P.M. Skarstad, J. Power Sources, 96 (2001) 33

[65] W. Greatbatch, V.C.F. Holmes, E.S. Takeuchi, S.J. Ebel, Pacing \& Clinical Electrophysiology 19 (1996) 1836

[66] E.S. Takeuchi, J. Power Sources, 54 (1995) 115

[67] J. Drews, G. Fehrmann, R. Staub, R. Wolf, J. Power Sources 97-8 (2001) 747

[68] S. Passerini, F. Coustier, B.B. Owens, J. Power Sources 90 (2000) 144; ibid 97-8 (2001) 750

[69] S.R. Ruben, US Patent 2,422,045 (1947)

[70] O.J. Adlhart, P. Rohonyi, D. Modroukass, J. Driller, Asaio J. 43 (1997) 214

[71] S.A. Hashmi, R.J. Latham, R.G. Linford, W.S. Schlindwein, Ionics 3 (1997) 177

[72] R.A. Huggins, Solid State Ionics 134 (2000) 179

[73] R.S. Rubino, H. Gan, E.S. Takeuchi, J. Electrochem. Soc. 148 (2001) A1029

[74] R.L. Newsom, W.C. Dillard, R.M. Nelms, IEEE Trans. Ind. Elect. 49 (2002) 1146

[75] G. Georg, M. Kirstein, R. Erbel, Hertz 26 (2001) 64

[76] H.Goto, T.Sugiura, Y.Harada, T.Kazui, Med. Biol. Engng. Comp. 37 (1999) 377

[77] A.V.D. Tchin-Iou, B.G. Min, Int. J. Artificial Organs, 22 (1999) 823

[78] C.P. Gale, G.P. Mulley, J. Roy. Soc. Medicine, 95 (2002) 353

[79] P. Bro in: Power Sources 7 (Academic Press, London, 1979) p. 571

[80] W.A. Webb, Gastrointestinal Endoscopy 41 (1995) 39 